\title{
ORIGINAL ARTICLE Reference values of whole-blood fatty acids by age and sex from European children aged 3-8 years
}

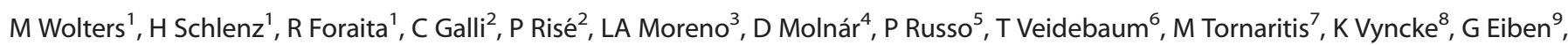
$\mathrm{L}_{\text {lacoviello }}{ }^{10,11}$ and $\mathrm{W}$ Ahrens $\mathrm{s}^{1,12}$ on behalf of the IDEFICS consortium

OBJECTIVES: To establish reference values for fatty acids (FA) especially for $n-3$ and $n-6$ long-chain polyunsaturated FAs (LC PUFA) in whole-blood samples from apparently healthy 3-8-year-old European children. The whole-blood FA composition was analysed and the age- and sex-specific distribution of FA was determined.

DESIGN AND SUBJECTS: Blood samples for FA analysis were taken from 2661 children of the IDEFICS (identification and prevention of dietary- and lifestyle-induced health effects in children and infants) study cohort. Children with obesity $(n=454)$ and other diseases that are known to alter the FA composition $(n=450)$ were excluded leaving 1653 participants in the reference population. MEASUREMENTS: The FA composition of whole blood was analysed from blood drops by a rapid, validated gas chromatographic method.

RESULTS: Pearson correlation coefficients showed an age-dependent increase of C18:2n-6 and a decrease of C18:1n-9 in a subsample of normal weight boys and girls. Other significant correlations with age were weak and only seen either in boys or in girls, whereas most of the FA did not show any age dependence. For age-dependent n-3 and n- 6 PUFA as well as for other FA that are correlated with age (16:0, C18:0 and C18:1n-9) percentiles analysed with the general additive model for location scale and shape are presented. A higher median in boys than in girls was observed for C20:3n-6, C20:4n-6 and C22:4n-6.

CONCLUSIONS: Given the reported associations between FA status and health-related outcome, the provision of FA reference ranges may be useful for the interpretation of the FA status of children in epidemiological and clinical studies.

International Journal of Obesity (2014) 38, S86-S98; doi:10.1038/ijo.2014.139

\section{INTRODUCTION}

Fatty acids (FA) not only serve as major substrates for energy production but also fulfil several physiological functions. In this respect, the main focus is on polyunsaturated fatty acids (PUFA) such as alpha-linolenic acid (C18:3n-3) and linoleic acid (C18:2n-6) and, particularly, on long-chain PUFA (LC PUFA) such as eicosapentaenoic acid (C20:5n-3) and docosahexaenoic acid $(C 22: 6 n-3)$ of the $n-3$ series and arachidonic acid (C20:4n-6) of the $n-6$ series. LC PUFA have a major role in the structure and function of cell membranes influencing their fluidity and permeability. In addition, they serve as precursors for the production of eicosanoids, such as prostaglandins, leukotrienes and thromboxanes, and docosanoids such as D-series resolvins and protectins with various effects, for example, on vasodilation, platelet aggregation, inflammation, cell growth and cell proliferation. ${ }^{1}$ As a result LC PUFA influence normal growth, neurological and visual development as well as cognitive and immune function. Thus, an adequate status of LC PUFA is especially important in children.

The blood FA composition reflects the dietary fat intake, ${ }^{2}$ especially LC n-3 PUFA are strongly correlated with intake. ${ }^{3,4}$ This is why impaired PUFA availability may occur in children with unbalanced diet, malabsorption or maldigestion syndrome $e^{5}$ and diseases of the liver where chain elongation and desaturation of LC PUFA are mainly located. ${ }^{6,7}$ Beyond limited bioavailability and metabolism, monitoring of the blood FA becomes increasingly important because a vast number of studies have reported a modified blood PUFA distribution in various diseases. In particular, the most common chronic childhood diseases ${ }^{8,9}$ in western countries, for example, asthma, ${ }^{10-12}$ cystic fibrosis, ${ }^{13,14}$ obesity, ${ }^{15,16}$ diabetes, ${ }^{17,18}$ mental health problems especially depression ${ }^{19,20}$ and attention-deficity/hyperactivity disorders (ADHD) ${ }^{21,22}$ are associated with modifications of the blood FA composition. Moreover, some studies have shown significant associations between the disease outcome and the LC PUFA profile, indicating beneficial effects of n-3 LC PUFA. Recently, it has also been shown that the serum cholesterylester FA profile in childhood is associated with the carotid intima media thickness in adult females ${ }^{23}$ and with blood pressure in males and, to a lesser extent, also in females. ${ }^{24}$ Besides dietary intake, the activity of the enzymes involved in the conversion of FA to LC PUFA, delta-9 desaturase (stearoyl-CoA desaturase1, SCD-1), delta- 6 desaturase (D6D) and delta-5 desaturase (D5D), also have an important role for the FA composition because they are rate limiting in the

${ }^{1}$ Leibniz Institute for Prevention Research and Epidemiology_BIPS, Bremen, Germany; ${ }^{2}$ DiSFeB, Department of Pharmacological and Biomolecular Sciences, University of Milan, Milan, Italy; ${ }^{3}$ Growth, Exercise, Nutrition and Development (GENUD) Research Group, University of Zaragoza, Zaragoza, Spain; ${ }^{4}$ National Institute of Health Promotion, University of Pécs, Pécs, Hungary; ${ }^{5}$ Epidemiology and Population Genetics, Institute of Food Sciences, National Research Council, Avellino, Italy; ${ }^{6}$ Department of Chronic Diseases, National Institute for Health Development, Tallinn, Estonia; ${ }^{7}$ Research and Education Institute of Child Health, Strovolos, Cyprus; ${ }^{8}$ Department of Public Health, Faculty of Medicine and Health Sciences, Ghent University, Ghent, Belgium; ${ }^{9}$ Department of Public Health and Community Medicine, Queen Silvia Children's Hospital, Gothenburg, Sweden; ${ }^{10}$ Laboratory of Molecular and Nutritional Epidemiology, Department of Epidemiology and Prevention, IRCCS Istituto Neurologico Mediterraneo Neuromed, Pozzilli, Italy; ${ }^{11}$ Laboratory of Cardiovascular and Neurovascular Epidemiology, Casa di Cura Montevergine, Mercogliano, Italy and ${ }^{12}$ Institute of Statistics, Faculty of Mathematics and Computer Science, University of Bremen, Bremen, Germany. Correspondence: Dr M Wolters, Unit Lifestyle Related Disorders, Department Epidemiological Methods and Etiologic Research, Leibniz Institute for Prevention Research and Epidemiology-BIPS, Achterstrasse 30, 28359 Bremen, Germany.

E-mail: wolters@bips.uni-bremen.de 
biosynthesis of monounsaturated FA and LC PUFA. A high SCD-1 index has shown to be associated with obesity, whereas the D5D and D6D indices are associated with insulin sensitivity and metabolic syndrome. ${ }^{15,25,26}$

Whereas national data on the blood FA composition of young children stem mainly from small and a few large study populations, ${ }^{27-29}$ international data from unselected populations are missing. Therefore, we aim to establish reference values for 3-8-year-old European children.

\section{SUBJECTS AND METHODS}

Subjects

A subsample of the IDEFICS (identification and prevention of dietary- and lifestyle-induced health effects in children and infants) cohort was included in this study. In IDEFICS, 16228 children aged 2-9 years were examined in a population-based baseline survey in eight European countries ranging from North to South and from East to West (Belgium, Cyprus, Estonia, Germany, Hungary, Italy, Spain and Sweden) from autumn 2007 to spring 2008. This baseline survey $\left(T_{0}\right)$ was the starting point of the prospective cohort study with the largest European children's cohort established to date. ${ }^{30}$ Additional 2517 children aged $2.0-10.9$ years were newly recruited during a second survey $\left(T_{1}\right) 2$ years later; the study design has been described in detail elsewhere. ${ }^{30}$ A subsample of the $T_{0}$ and $T_{1}$ IDEFICS cohort is included in the present analysis.

\section{Inclusion and exclusion criteria for reference population}

FA composition was analysed in a subsample of IDEFICS participants with oversampling of overweight and obese children. Therefore, weights were constructed as described in the section 'Statistical methods'. The reasons for oversampling were the focus of the IDEFICS study on overweight and obesity and a planned nested case-control study. Overall 2661 FA profiles from fasting blood samples of children aged $2.0-10.9$ years were analysed. Of these, 1008 children were excluded for various reasons (Figure 1): 454 were defined as obese according to Cole and Lobstein ${ }^{31}$ and 450 children had other diagnosed diseases (allergies, asthma, major dermatological problems, chronic rheumatic disease and diabetes mellitus) that may influence the FA composition. In addition, the upper and lower age strata included too few children for the analysis leaving 1653 participants aged 3.0-8.9 years in our analysis group.

Blood FA sampling and analysis

Blood samples were obtained by collecting a drop of blood from a fingertip or by venipuncture. A drop of native blood was then applied directly to a test strip prepared with butylated hydroxytoluene as an antioxidant. The dried strip was placed in a plastic envelope and shipped to the laboratory. FA in blood lipids were separated and determined by gas-liquid chromatography after direct derivatisation to their methyl esters without prior extraction of total lipids from the samples as previously described. ${ }^{32}$ In brief, the strip of paper was transferred to Teflon screw-capped glass vials with $1 \mathrm{ml} 3 \mathrm{~N} \mathrm{MeOH} / \mathrm{HCl}$ and placed in a dry bath at $90^{\circ} \mathrm{C}$ for $1 \mathrm{~h}$. Afterwards, $2 \mathrm{ml}$ of water and $2 \mathrm{ml}$ of a saturated $\mathrm{KCl}$ solution were added and FA methyl esters were then extracted using $2 \mathrm{ml}$ of $\mathrm{n}$-hexane twice. After centrifugation $\left(1000 \mathrm{~g}\right.$ for $5 \mathrm{~min}$ at $4-5^{\circ} \mathrm{C}$ ), the FA methyl esters recovered in the upper $n$-hexane phase were dried under nitrogen flow and vacuum by evaporating the solvent ( $n$-hexane), then they were redissolved in about $50 \mu \mathrm{l} n$-hexane and taken up. Finally, $1 / 100$ th volume was injected in a gas-liquid chromatography (model GC1000, DANI Instruments SpA, Cologno Monzese, Italy) equipped with a capillary column with $30 \mathrm{~m}$ length, $0.32 \mathrm{~mm}$ inner diameter and $0.25 \mu \mathrm{m}$ film thickness in poly-ethylene-glycol (Omegawax 320 Supelco, Bellefonte, PA, USA), a programmed temperature vaporising injector and a flame ionisation detector to quantify individual FA methyl esters, and a dedicated data system. Temperature programming went from $120^{\circ} \mathrm{C}$ for $1.20 \mathrm{~min}$, with an increase of $2.7^{\circ} \mathrm{C}$ per min to $205^{\circ} \mathrm{C}$, a 15 -min hold period, then with an increment of $5^{\circ} \mathrm{C}$ per min to $220^{\circ} \mathrm{C}$ and a 15 -min hold period. For identification of the peaks pure reference compounds were used.

\begin{tabular}{|c|c|c|}
\hline \multirow[t]{2}{*}{ Sex } & Girls, n (\%) & Boys, n (\%) \\
\hline & 836 (50.6\%) & $817(49.4 \%)$ \\
\hline \multicolumn{3}{|l|}{ Age categories } \\
\hline $3-<4$ years & $128(15.3 \%)$ & $123(15.1 \%)$ \\
\hline $4-<5$ years & 147 (17.6\%) & $144(17.6 \%)$ \\
\hline $5-<6$ years & $103(12.3 \%)$ & $106(13.0 \%)$ \\
\hline $6-<7$ years & 125 (15.0\%) & $139(17.0 \%)$ \\
\hline $7-<8$ years & $197(23.6 \%)$ & $180(22.0 \%)$ \\
\hline \multirow[t]{2}{*}{$8-<9$ years } & $136(16.3 \%)$ & $125(15.3 \%)$ \\
\hline & Mean (s.d.) & Mean (s.d.) \\
\hline Age, years & $6.09(1.72)$ & $6.05(1.69)$ \\
\hline Weight, kg & $23.26(6.25)$ & $23.43(6.28)$ \\
\hline Height, $\mathrm{cm}$ & 117.10 (11.99) & 117.83 (12.09) \\
\hline BMI, $\mathrm{kg} \mathrm{m}^{-2}$, unweighted & 16.67 (1.96) & $16.58(1.89)$ \\
\hline BMI, $\mathrm{kg} \mathrm{m}^{-2}$, weighted & $16.03(1.79)$ & $16.11(1.71)$ \\
\hline BMI $z$-score, unweighted & $0.57(1.02)$ & $0.47(1.07)$ \\
\hline BMI z-score, weighted & $0.23(0.99)$ & $0.20(1.02)$ \\
\hline
\end{tabular}

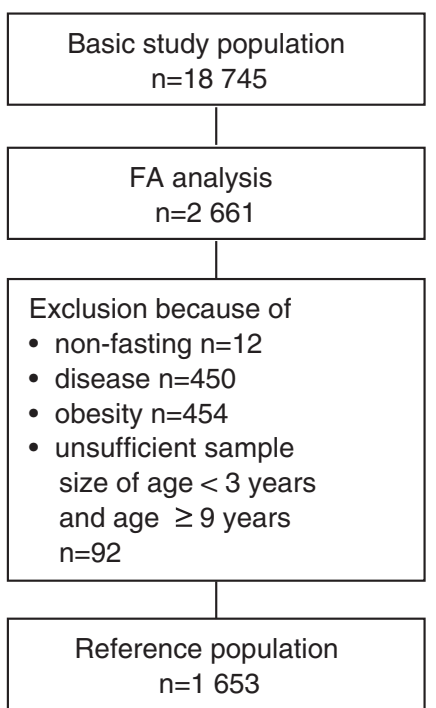

Figure 1. Flow chart of subject inclusion and exclusion. 
The FA composition is expressed as weight percentage of all FA detected (\% wt/wt) with a $\mathrm{C} 16-\mathrm{C} 24$ chain length excluding trans FA. The following FA were measured: C16:0, C18:0, C20:0, C22:0, C24:0, C16:1, C18:1n-9, C18:1n-7, C20:1, C22:1, C24:1, C20:3n-9, C18:2n-6, C18:3n-6, C20:3n-6, C20:4n-6, C22:4n-6, C22:5n-6, C18:3n-3, C20:5n-3, C22:5n-3 and $\mathrm{C} 22: 6 \mathrm{n}-3$. The desaturase indices were determined as follows:
SCD-1—C16:1n-7/16:0 (SCD-16), C18:1n-9/C18:0 (SCD-18); D6D—C20:3n-6/ C18:2n-6; D5D-C20:4n-6/C20:3n-6.

\section{Statistical methods}

Oversampling led to a high percentage of overweight children in the sample. Therefore, weights were constructed to match the distribution of

\section{Girls}

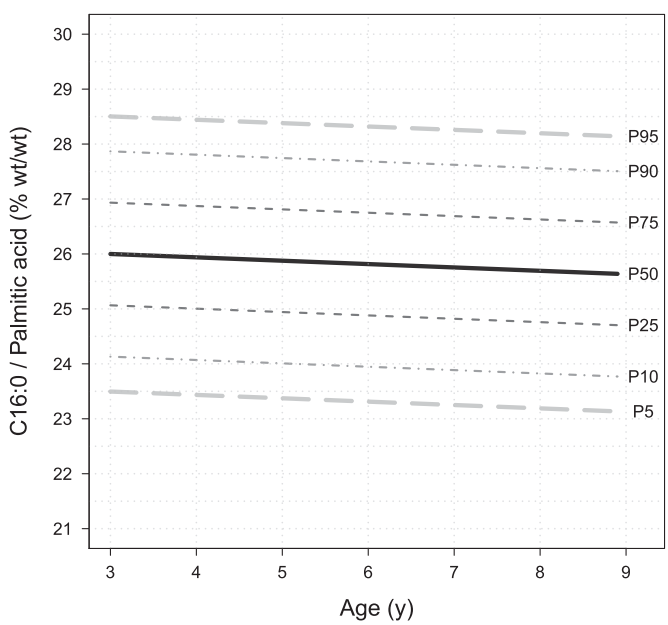

Girls

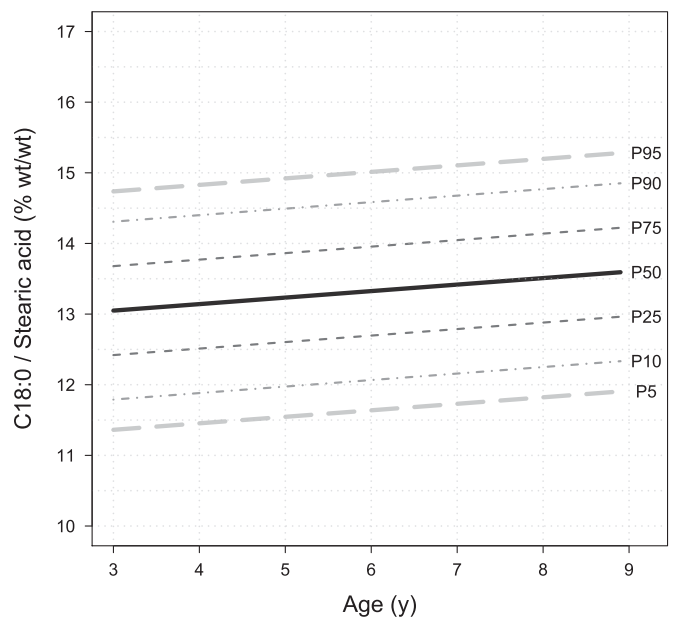

Girls

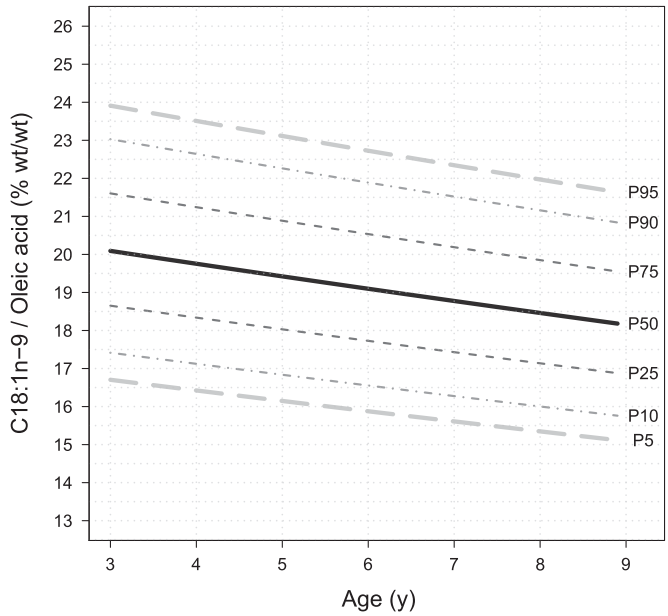

Boys

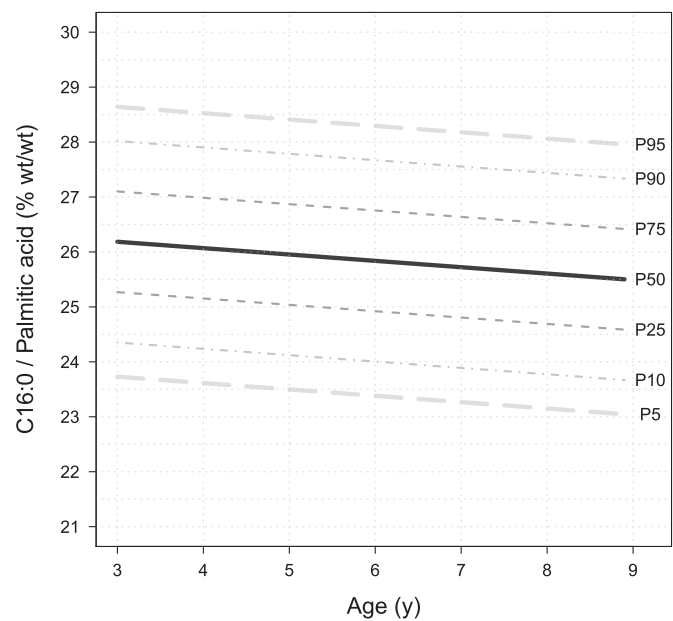

Boys

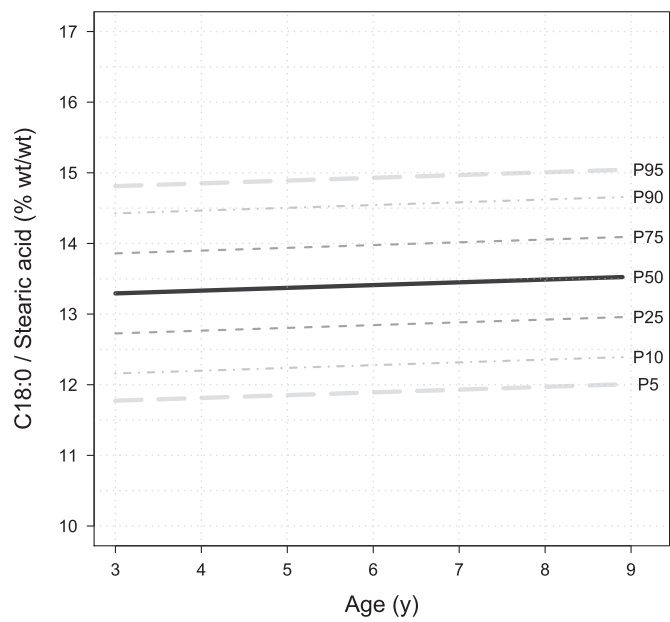

Boys

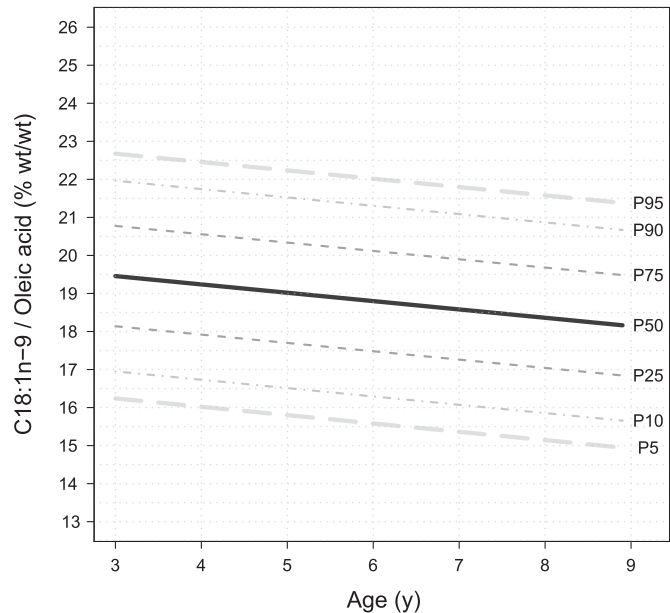

Figure 2. Percentiles (\% wt/wt) of selected FA in 3-8-year-old girls and boys calculated with GAMLSS. 
Girls

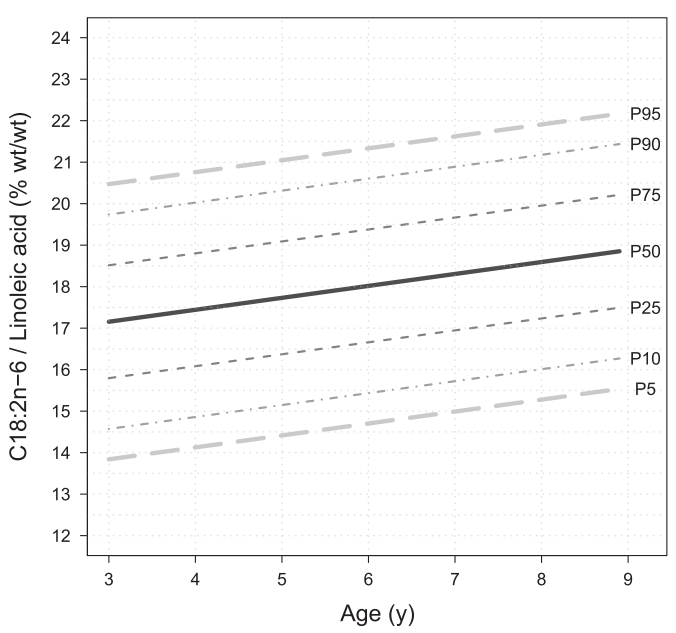

Girls

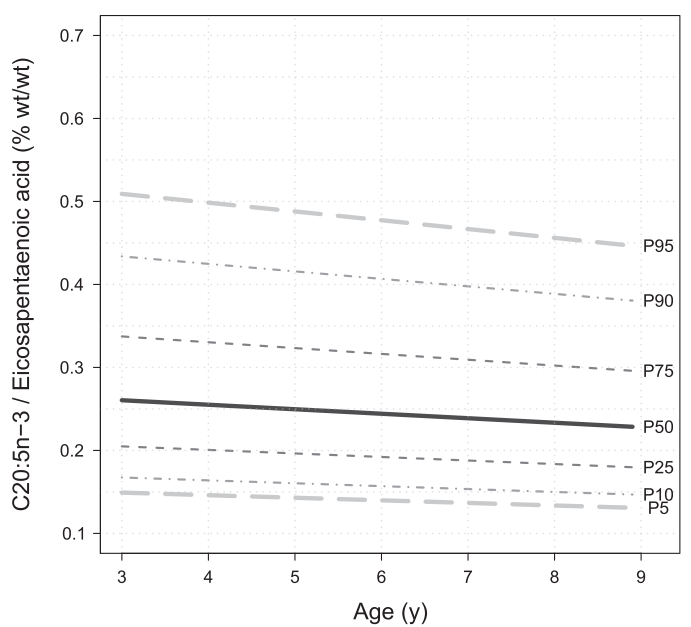

Girls

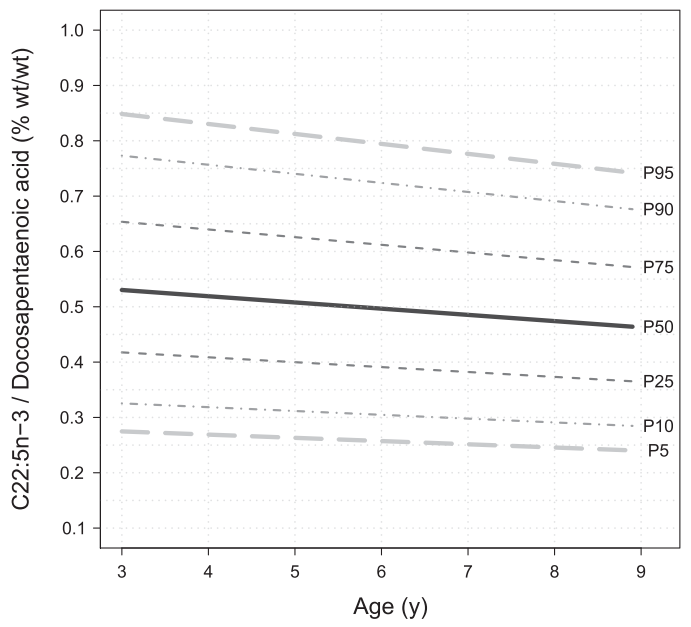

Figure 2. (Continued)

non-obese children from IDEFICS by sex and 1-year age groups. These weights are used in all analyses and for results presented in the paper except for analysis conducted in normal weight children.

Since the percentiles of most FA seemed to be similar across the age groups Pearson correlation coefficients were used to detect age dependence in a subsample of normal weight boys and girls $(n=1059$, 536 boys, 523 girls). A cut-off of $a=0.01$ and a correlation in both, boys and girls, were used to decide which FA should be included in the further
Boys

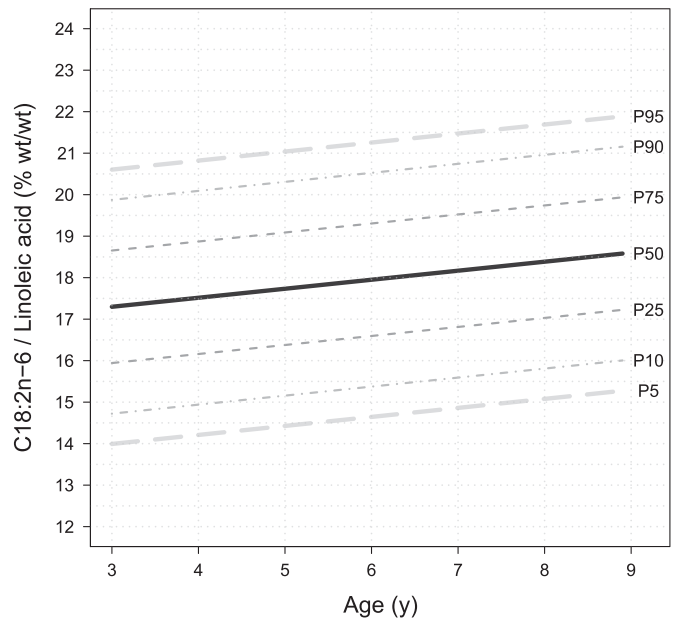

Boys

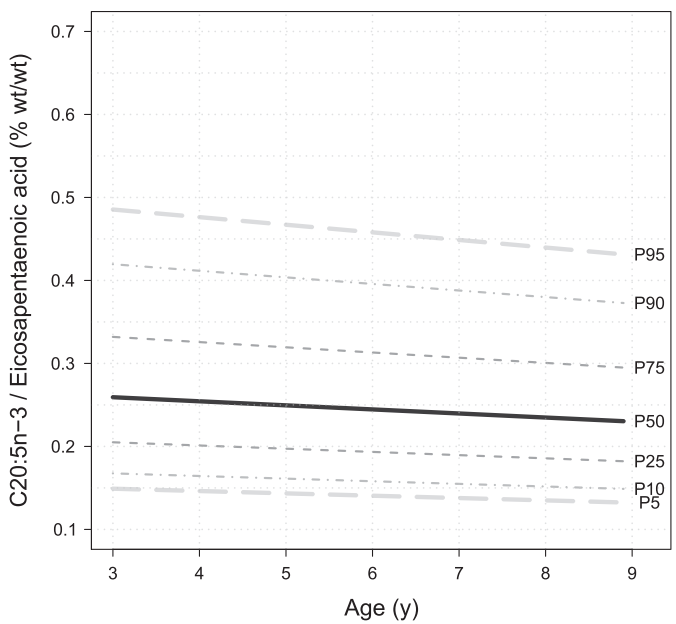

Boys

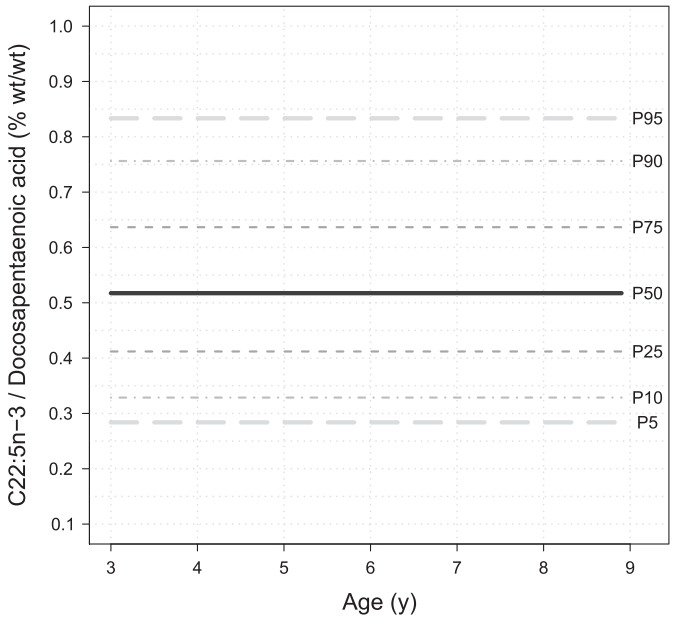

analysis with generalized additive models for location scale and shape (GAMLSS). Despite being correlated with age only in boys, C16:0 was also included because of its high proportion in blood. Moreover, the most important n-3 and n-6 PUFA and LC PUFA (except for C18:3n-3, C22:6n-3 and C20:4n-6 because no age dependence was seen) were included in analysis with GAMLSS. We calculated percentile curves as a function of age stratified by sex using the GAMLSS method as extension of the LMS method. The LMS method models three parameters: the skewness (L) 
accounts for the deviation from a normal distribution using a Box-Cox transformation, the median (M) accounts for the dependence of the outcome variable on one explanatory variable and the coefficient of variation (S) accounts for the variation of data points around the mean and adjusts for non-uniform dispersion. The GAMLSS method is able to model more than one covariate and also other distributions. We used the gamlss package (version 4.2-6) of the statistical software $R$ (version 3.0.1). ${ }^{33}$ Different distributions, that is, the Box-Cox-Power-Exponential, Box-Cox $t$ Box-Cox Cole and Green (BCCG), gamma, inverse Gaussian, logistic, $t$ family and normal distribution were fitted to the observed distribution of FA. Moreover, the influence of age on parameters of the considered distributions were modelled as a constant, as a linear function or as a cubic spline of the covariates.

Goodness-of-fit was assessed by the Bayesian information criterion and Q-Q plots to select the final model including the fitted distribution of FA and the influence of the covariates on distribution parameters. Worm plots were used as a diagnostic tool to assess whether adjustment for kurtosis was required. ${ }^{34}$ Finally, curves for the 5th, 10th, 25th, 50th, 75th, 90th and 95th percentiles were calculated for C16:0, C18:0, C18:1n-9, C18:2n-6, C20:5n-3 and C22:5n-3 on the basis of the model that showed the best goodness-of-fit. ${ }^{33,35}$ The best fit in GAMLSS was reached for C16:0 and C18:0 using the logistic distribution with parameters modelled as follows in both sexes: $\mu$ linearly and $\log (\sigma)$ as a constant; for $C 18: 1 n-9$ using the gamma distribution with parameters modelled as follows: $\log (\mu)$ linearly and $\log (\sigma)$ as constant; for C18:2n- 6 using a normal distribution with $\mu$ modelled linearly and $\log (\sigma)$ modelled as a constant; for C20:5n-3 using the BCCG distribution with parameters modelled as follows: $\mu$ linearly and log $(\sigma)$ and $v$ as constants. The best fit for $C 22: 5 n-3$ was reached using the BCCG distribution without age dependence for boys and for girls using the BCCG distribution where the parameters were modelled as follows: $\mu$ linearly and $\log (\sigma)$ and $v$ as constants.

Percentiles of the other FA were not calculated with GAMLSS; the most interesting of them were pooled for the age groups and are presented as boxplots.

Sensitivity analysis using GAMLSS was conducted for all FA calculated with GAMLSS regarding the influence of obesity. In addition, for these FA, further GAMLSS analyses were conducted based on the data set including obese children and children with diseases.

\section{RESULTS}

The characteristics of the study population with weighted and unweighted body mass index and body mass index $z$-score are presented in Table 1.

Table 3. Percentiles of FA composition (\% wt/wt) calculated with GAMLSS

\begin{tabular}{|c|c|c|c|c|c|c|c|c|c|c|c|c|c|c|c|c|c|}
\hline \multirow[t]{2}{*}{$F A$} & \multirow[t]{2}{*}{ Age } & \multicolumn{7}{|c|}{ Percentile for girls } & \multirow[t]{2}{*}{$F A$} & \multirow[t]{2}{*}{ Age } & \multicolumn{7}{|c|}{ Percentile for boys } \\
\hline & & 5 & 10 & 25 & 50 & 75 & 90 & 95 & & & 5 & 10 & 25 & 50 & 75 & 90 & 95 \\
\hline \multirow[t]{7}{*}{ C16:0 } & & & & & & & & & C16:0 & & & & & & & & \\
\hline & $3-<4$ & 23.47 & 24.10 & 25.04 & 25.97 & 26.90 & 27.84 & 28.47 & & $3-<4$ & 23.67 & 24.30 & 25.21 & 26.13 & 27.04 & 27.96 & 28.58 \\
\hline & $4-<5$ & 23.40 & 24.04 & 24.97 & 25.91 & 26.84 & 27.78 & 28.41 & & $4-<5$ & 23.56 & 24.18 & 25.10 & 26.01 & 26.93 & 27.84 & 28.47 \\
\hline & $5-<6$ & 23.34 & 23.98 & 24.91 & 25.85 & 26.78 & 27.72 & 28.35 & & $5-<6$ & 23.44 & 24.06 & 24.98 & 25.90 & 26.81 & 27.73 & 28.35 \\
\hline & $6-<7$ & 23.28 & 23.92 & 24.85 & 25.79 & 26.72 & 27.65 & 28.29 & & $6-<7$ & 23.32 & 23.95 & 24.86 & 25.78 & 26.70 & 27.61 & 28.24 \\
\hline & $7-<8$ & 23.22 & 23.86 & 24.79 & 25.72 & 26.66 & 27.59 & 28.23 & & $7-<8$ & 23.21 & 23.83 & 24.75 & 25.66 & 26.58 & 27.50 & 28.12 \\
\hline & $8-<9$ & 23.16 & 23.79 & 24.73 & 25.66 & 26.60 & 27.53 & 28.17 & & $8-<9$ & 23.09 & 23.72 & 24.63 & 25.55 & 26.47 & 27.38 & 28.00 \\
\hline \multirow[t]{7}{*}{ C18:0 } & & & & & & & & & C18:0 & & & & & & & & \\
\hline & $3-<4$ & 11.41 & 11.84 & 12.47 & 13.10 & 13.73 & 14.36 & 14.78 & & $3-<4$ & 11.79 & 12.18 & 12.75 & 13.31 & 13.88 & 14.45 & 14.83 \\
\hline & $4-<5$ & 11.50 & 11.93 & 12.56 & 13.19 & 13.82 & 14.45 & 14.88 & & $4-<5$ & 11.83 & 12.22 & 12.79 & 13.35 & 13.92 & 14.49 & 14.87 \\
\hline & $5-<6$ & 11.59 & 12.02 & 12.65 & 13.28 & 13.91 & 14.54 & 14.97 & & $5-<6$ & 11.87 & 12.26 & 12.82 & 13.39 & 13.96 & 14.52 & 14.91 \\
\hline & $6-<7$ & 11.68 & 12.11 & 12.74 & 13.37 & 14.00 & 14.63 & 15.06 & & $6-<7$ & 11.91 & 12.30 & 12.86 & 13.43 & 14.00 & 14.56 & 14.95 \\
\hline & $7-<8$ & 11.78 & 12.20 & 12.83 & 13.46 & 14.09 & 14.72 & 15.15 & & $7-<8$ & 11.95 & 12.34 & 12.90 & 13.47 & 14.04 & 14.60 & 14.99 \\
\hline & $8-<9$ & 11.87 & 12.30 & 12.93 & 13.56 & 14.19 & 14.82 & 15.24 & & $8-<9$ & 11.99 & 12.38 & 12.94 & 13.51 & 14.08 & 14.64 & 15.03 \\
\hline \multirow[t]{7}{*}{ C18:1n-9 } & & & & & & & & & C18:1n-9 & & & & & & & & \\
\hline & $3-<4$ & 16.56 & 17.27 & 18.50 & 19.92 & 21.42 & 22.84 & 23.71 & & $3-<4$ & 16.13 & 16.84 & 18.03 & 19.35 & 20.67 & 21.85 & 22.56 \\
\hline & $4-<5$ & 16.29 & 16.98 & 18.18 & 19.59 & 21.06 & 22.45 & 23.31 & & $4-<5$ & 15.91 & 16.62 & 17.81 & 19.13 & 20.45 & 21.64 & 22.35 \\
\hline & $5-<6$ & 16.01 & 16.69 & 17.88 & 19.26 & 20.71 & 22.08 & 22.92 & & $5-<6$ & 15.69 & 16.40 & 17.59 & 18.91 & 20.23 & 21.42 & 22.13 \\
\hline & $6-<7$ & 15.74 & 16.41 & 17.58 & 18.94 & 20.36 & 21.70 & 22.54 & & $6-<7$ & 15.47 & 16.18 & 17.37 & 18.69 & 20.01 & 21.20 & 21.91 \\
\hline & $7-<8$ & 15.48 & 16.14 & 17.28 & 18.62 & 20.02 & 21.34 & 22.16 & & $7-<8$ & 15.25 & 15.96 & 17.15 & 18.47 & 19.79 & 20.98 & 21.69 \\
\hline & $8-<9$ & 15.22 & 15.87 & 16.99 & 18.31 & 19.68 & 20.98 & 21.78 & & $8-<9$ & 15.03 & 15.75 & 16.93 & 18.25 & 19.57 & 20.76 & 21.47 \\
\hline \multirow[t]{7}{*}{ C18:2n-6 } & & & & & & & & & C18:2n-6 & & & & & & & & \\
\hline & $3-<4$ & 13.98 & 14.72 & 15.94 & 17.30 & 18.66 & 19.88 & 20.61 & & $3-<4$ & 14.10 & 14.83 & 16.05 & 17.41 & 18.76 & 19.98 & 20.71 \\
\hline & $4-<5$ & 14.27 & 15.00 & 16.23 & 17.59 & 18.95 & 20.17 & 20.90 & & $4-<5$ & 14.32 & 15.05 & 16.27 & 17.62 & 18.98 & 20.20 & 20.93 \\
\hline & $5-<6$ & 14.56 & 15.29 & 16.52 & 17.87 & 19.23 & 20.46 & 21.19 & & $5-<6$ & 14.54 & 15.27 & 16.49 & 17.84 & 19.20 & 20.42 & 21.15 \\
\hline & $6-<7$ & 14.85 & 15.58 & 16.80 & 18.16 & 19.52 & 20.75 & 21.48 & & $6-<7$ & 14.75 & 15.48 & 16.70 & 18.06 & 19.41 & 20.63 & 21.37 \\
\hline & $7-<8$ & 15.13 & 15.87 & 17.09 & 18.45 & 19.81 & 21.03 & 21.77 & & $7-<8$ & 14.97 & 15.70 & 16.92 & 18.28 & 19.63 & 20.85 & 21.58 \\
\hline & $8-<9$ & 15.42 & 16.15 & 17.38 & 18.74 & 20.10 & 21.32 & 22.05 & & $8-<9$ & 15.19 & 15.92 & 17.14 & 18.49 & 19.85 & 21.07 & 21.80 \\
\hline \multirow[t]{7}{*}{$C 20: 5 n-3$} & & & & & & & & & $C 20: 5 n-3$ & & & & & & & & \\
\hline & $3-<4$ & 0.15 & 0.17 & 0.20 & 0.26 & 0.33 & 0.43 & 0.50 & & $3-<4$ & 0.15 & 0.17 & 0.20 & 0.26 & 0.33 & 0.42 & 0.48 \\
\hline & $4-<5$ & 0.15 & 0.16 & 0.20 & 0.25 & 0.33 & 0.42 & 0.49 & & $4-<5$ & 0.15 & 0.16 & 0.20 & 0.25 & 0.32 & 0.41 & 0.47 \\
\hline & $5-<6$ & 0.14 & 0.16 & 0.19 & 0.25 & 0.32 & 0.41 & 0.48 & & $5-<6$ & 0.14 & 0.16 & 0.20 & 0.25 & 0.32 & 0.40 & 0.46 \\
\hline & $6-<7$ & 0.14 & 0.16 & 0.19 & 0.24 & 0.31 & 0.40 & 0.47 & & $6-<7$ & 0.14 & 0.16 & 0.19 & 0.24 & 0.31 & 0.39 & 0.45 \\
\hline & $7-<8$ & 0.14 & 0.15 & 0.19 & 0.24 & 0.31 & 0.39 & 0.46 & & $7-<8$ & 0.14 & 0.15 & 0.19 & 0.24 & 0.30 & 0.38 & 0.44 \\
\hline & $8-<9$ & 0.13 & 0.15 & 0.18 & 0.23 & 0.30 & 0.38 & 0.45 & & $8-<9$ & 0.13 & 0.15 & 0.18 & 0.23 & 0.30 & 0.38 & 0.44 \\
\hline \multirow[t]{7}{*}{$C 22: 5 n-3$} & & & & & & & & & $C 22: 5 n-3$ & & & & & & & & \\
\hline & $3-<4$ & 0.27 & 0.32 & 0.41 & 0.53 & 0.65 & 0.77 & 0.84 & & All & 0.28 & 0.33 & 0.41 & 0.52 & 0.64 & 0.76 & 0.83 \\
\hline & $4-<5$ & 0.27 & 0.32 & 0.40 & 0.51 & 0.63 & 0.75 & 0.82 & & & & & & & & & \\
\hline & $5-<6$ & 0.26 & 0.31 & 0.40 & 0.50 & 0.62 & 0.73 & 0.80 & & & & & & & & & \\
\hline & $6-<7$ & 0.25 & 0.30 & 0.39 & 0.49 & 0.61 & 0.72 & 0.79 & & & & & & & & & \\
\hline & $7-<8$ & 0.25 & 0.29 & 0.38 & 0.48 & 0.59 & 0.70 & 0.77 & & & & & & & & & \\
\hline & $8-<9$ & 0.24 & 0.29 & 0.37 & 0.47 & 0.58 & 0.68 & 0.75 & & & & & & & & & \\
\hline
\end{tabular}


Table 4. Precentiles of FA composition (\% wt/wt)

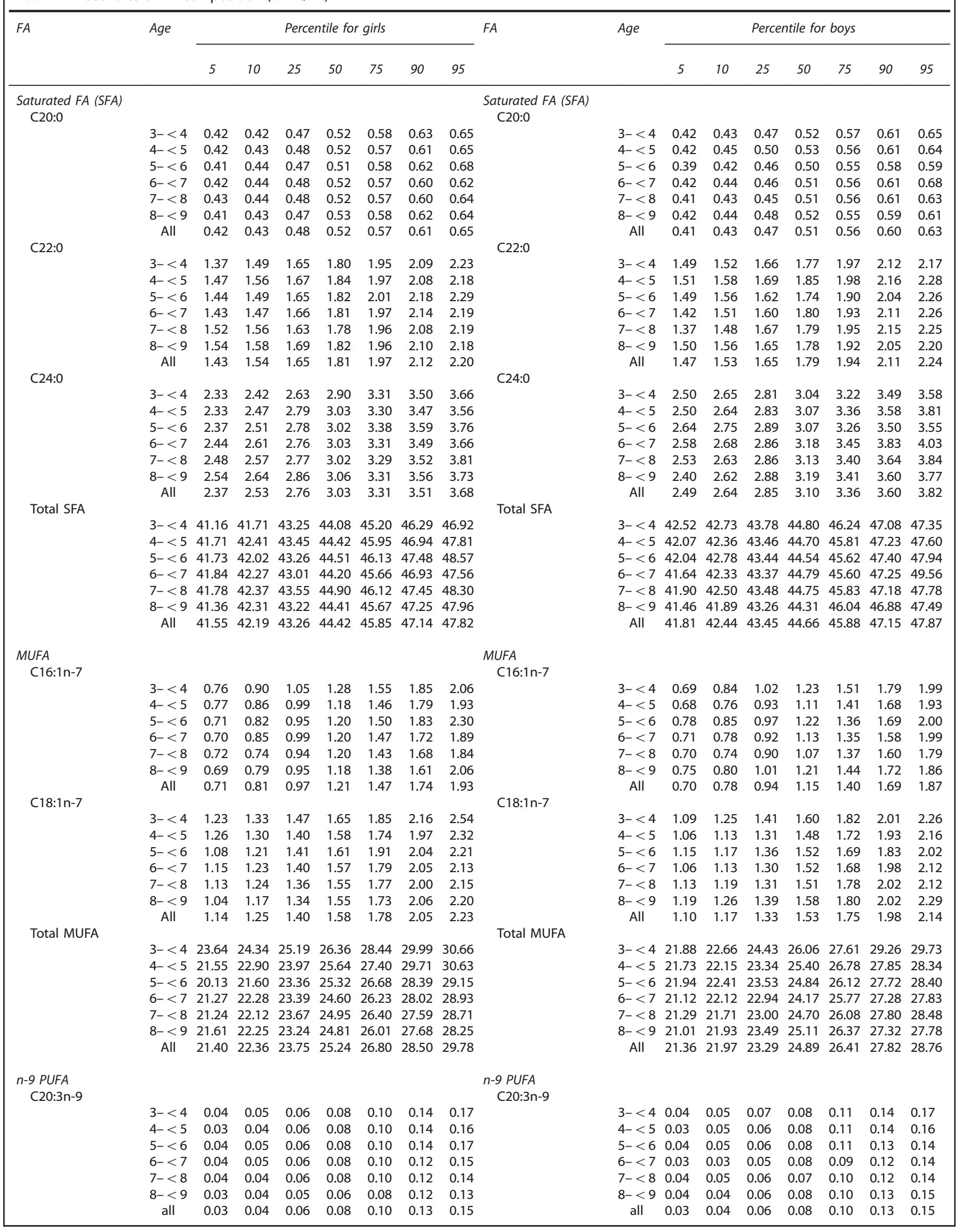


Table. 4. (Continued)

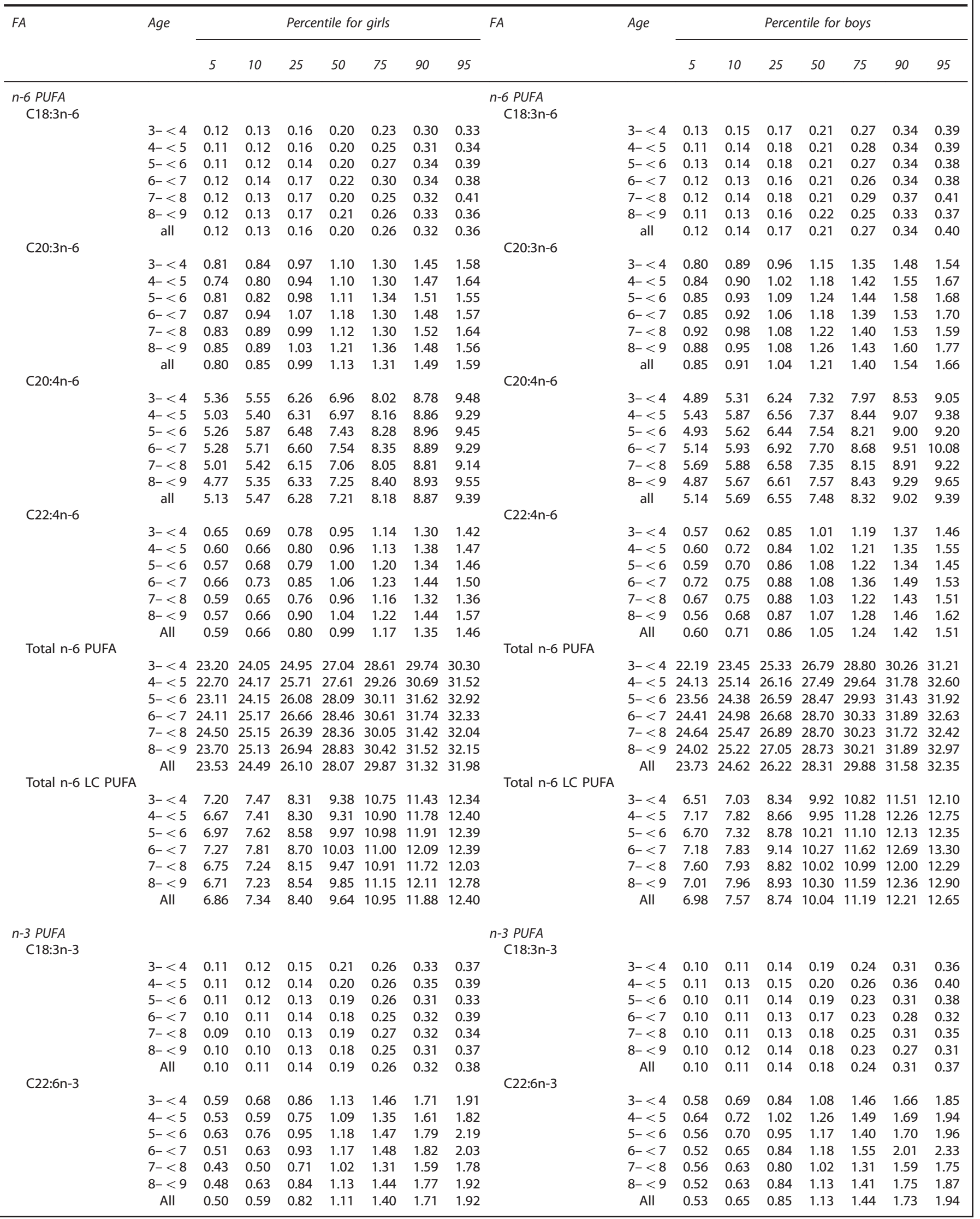


Table. 4. (Continued)

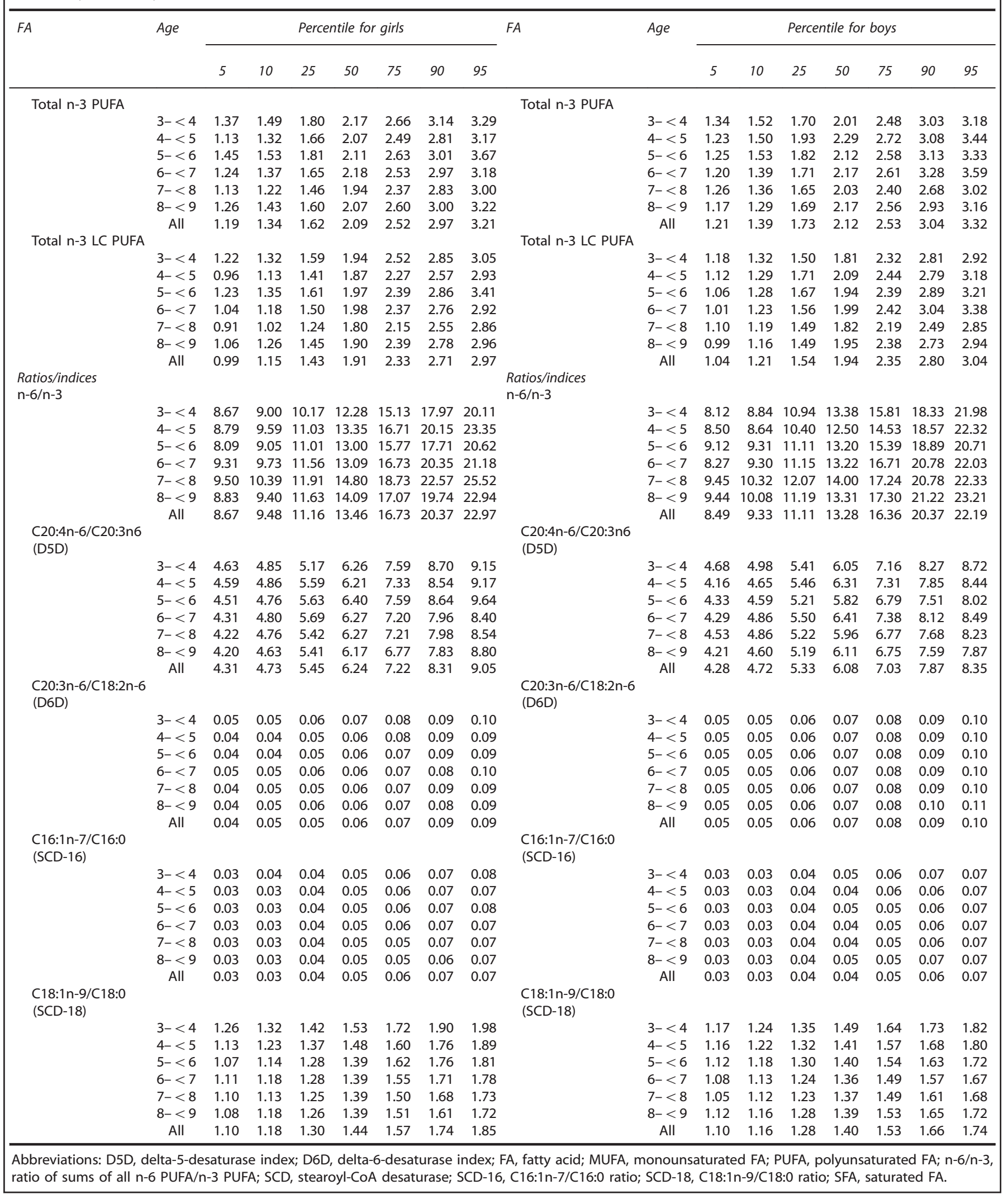


Significant but weak correlations of the FA proportion with age were seen for C18:1n-9, C18:2n-6 and sums of monounsaturated FA, PUFA and n-6 PUFA in both, girls and boys. Some age dependencies were only seen in either boys or in girls (Table 2).

C18:0 and C18:2n- 6 showed a positive trend with age, whereas this trend was negative for C16:0, C18:1n-9 and C20:5n-3 in both boys and girls (Figure 2). C22:5n-3 decreased in girls but not in boys. The corresponding percentiles based on GAMLSS are shown in Table 3. Only pooled percentiles are shown for $\mathrm{C} 22: 5 n-3$ in boys because no age-dependence was detected. Percentiles of the other FA, total saturated, unsaturated, polyunsaturated FA, n-6/n-3 ratio and important indices of enzyme activity stratified by sex and age as well as pooled for age groups are shown in Table 4. As most of those FA are not or only weakly correlated with age,
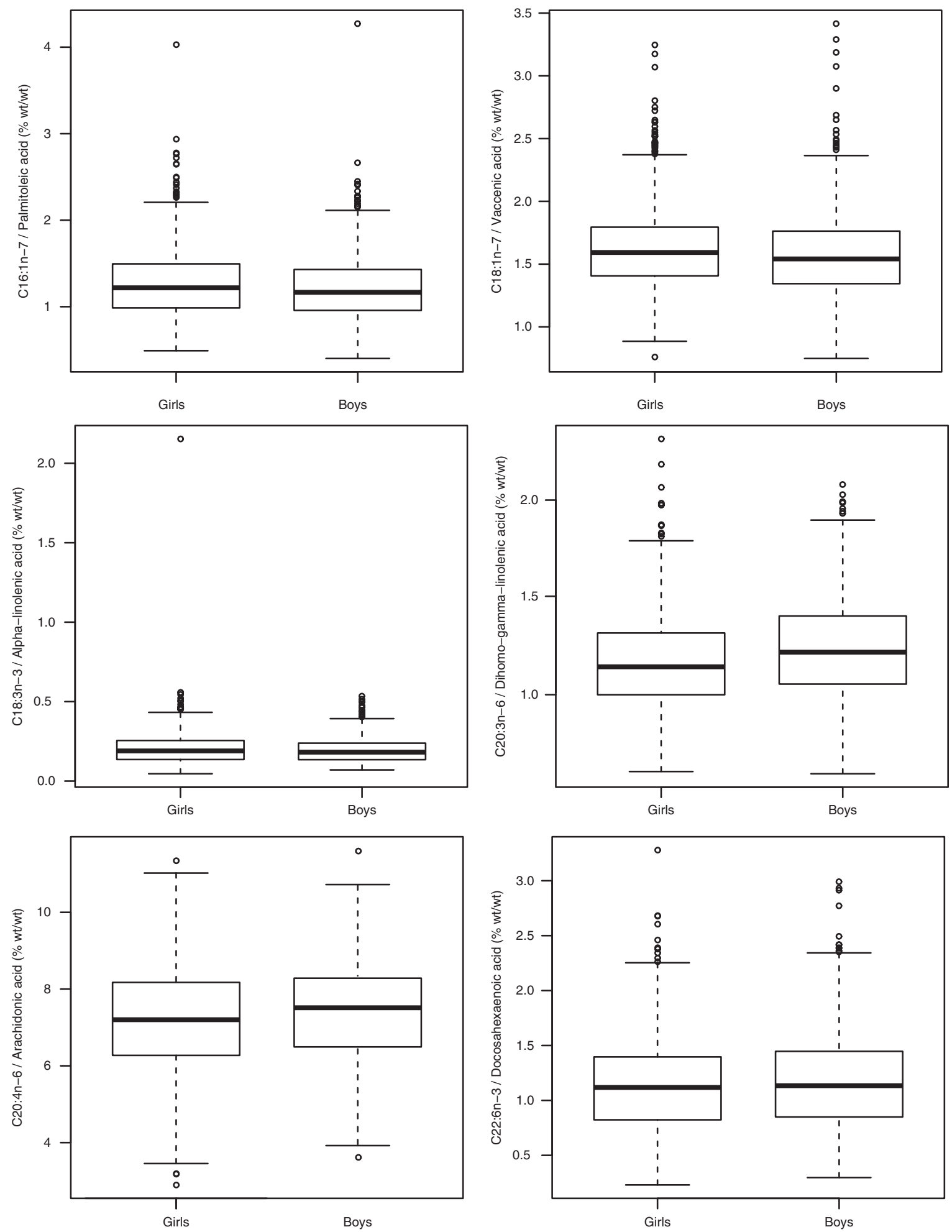

Figure 3. Proportion (\% wt/wt) of selected FA pooled for 3-8-year-old girls and boys. 

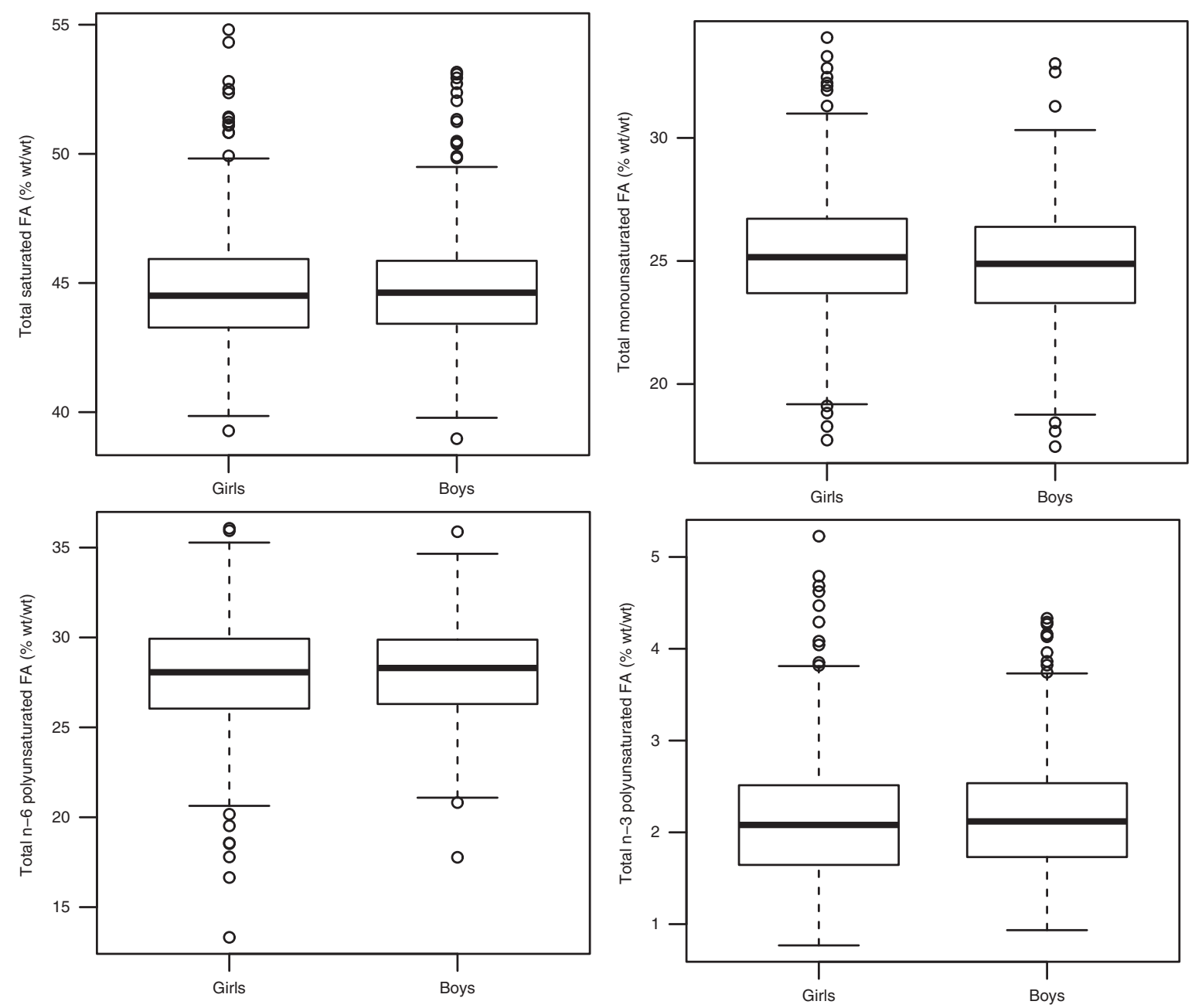

Figure 3. (Continued)

Figure 3 shows boxplots for the pooled percentage of selected FA in 3-8-year-old boys and girls.

Most FA levels were pretty similar in boys and girls but the median FA proportions of C20:3n-6, C20:4n-6 and C22:4n-6 seemed to be slightly higher in boys than in girls (Table 4 and Figure 3).

Sensitivity analysis regarding the influence of obesity according to common definitions from the World Health Organization, ${ }^{36,37}$ Centers for Disease Control, ${ }^{38}$ and Cole and Lobstein $^{31}$ showed only slightly deviating percentile curves when obese children were included (Supplementary Figure A). For the sake of completeness and to allow comparisons with other studies, percentiles of selected FA for the total study sample (including obese children and children with diseases) are shown in Supplementary Figure B and Supplementary Table A. They hardly differ from the percentiles in Figure 2 with the exception that the positive trend of C18:0 with age disappeared.

\section{DISCUSSION}

We have presented the whole-blood FA distributions for apparently healthy 3-8-year-old European girls and boys, and important indices as marker of enzyme activity that can be used as reference values in clinical and epidemiological studies. To our knowledge, the present study is the first to provide data on the FA composition of a large sample of European children.

Whole blood as the source of FA analysis

We used whole blood for FA analysis as that can easily be obtained from a drop of blood from the fingertip or venipuncture. A rapid and simple analysis method was used that allows FA measurement in large study populations and that was validated by several laboratories. ${ }^{32,39,40}$ Conventionally, FA were measured in plasma or serum reflecting short-term fat intake or in red blood cells (RBC) reflecting long-term fat intake. Whole-blood FA derive from both, plasma ( $54 \%$ by volume) and circulating cells ( $46 \%$ by volume), the latter predominantely consisting of $\mathrm{RBC} .{ }^{41}$ As cell membranes are comprised mainly of phospholipids that are particularly rich in LC PUFA such as C20:5n-3 and C22:6n-3 whole blood contains higher LC PUFA and lower PUFA percentages than serum. ${ }^{32}$ This is in line with data showing that the C20:5n-3 and C22:6n-3 content of the whole blood is highly correlated with that of RBC. ${ }^{42}$ Whole blood includes FA from all lipid classes with phospholipids of plasma and RBC being the main contributors of the FA amount and profile. Therefore, whole blood provides a balanced picture of the FA status and is representative for the total FA pool. ${ }^{39}$ Several studies confirmed that whole blood reflects the dietary FA intake and is a suitable marker for long-term essential FA intake. This is also true for n-3 FA that are reasonably 
stable in fasting whole blood and can therefore be used to determine n-3 FA status. ${ }^{4,32,43}$

Montgomery et $a l^{44}$ also used whole blood samples for FA measurement in 493 school children aged 7-9 years from Oxfordshire, UK, and found similar percentages of $n-6$ FA but markedly higher n-3 FA than in our sample. Whole blood FA have also been measured in a nested case-ontrol study of the Physicians' Health Study showing an $72 \%$ and $81 \%$ lower risk of sudden death in men with n-3 LC PUFA levels in the upper third and fourth quartiles, respectively, compared with the lowest quartile. $^{45}$ The values of $n-3$ and $n-6$ PUFA reported are considerably higher than in our study. Different values compared with our study may be explainable by differences in the analytical method and the range of FA measured. In addition, in the latter study they can also result from the higher age of the participants and an additional extraction step in the analysis compared with our method. ${ }^{45}$ Furthermore, the dietary intake may have been higher in both more homogenous study populations, ${ }^{44,45}$ whereas our sample is pretty heterogeneous and represents the FA composition of children with various dietary habits from throughout Europe.

\section{Age dependence of FA}

In the subsample of normal weight children, only a few FA were (weakly) associated with age. The analysis using GAMLSS revealed a negative association of C18:1n-9 and a positive association of C18:2n-6 and C18:0 with age.

Accordingly, in a large German sample of 2- and 6-year-old boys and girls, no major age dependencies were observed in the FA composition of serum glycerophospholipids. In line with the trend across the age groups in our sample, C18:2n- 6 was slightly higher and C18:1n-9 slightly lower in 6- compared with 2-year-old children. ${ }^{29}$

In the sample of 493 school children aged 7-9 years, children of the lowest age group (7 years) had higher C22:5n-3, C20:4n- 6 and C18:2n-6 than older children. ${ }^{44}$ Our data confirmed a decreasing trend of $C 22: 5 n-3$ with age in girls but we found C18:2n- 6 to increase with age and no age dependence for C20:4n-6.

Harris et al. ${ }^{4}$ measured erythrocyte FA in 160000 patients aged from 10 to 99 years and reported an increase of C22:6n-3 and C20:5n-3 and a decrease of C18:2n-6 over the first seven decades. Total saturated FA, total PUFA, C20:4n-6 and C18:3n-3 remained almost the same across all ages. A positive age trend of $C 18: 2 n-6$ or a negative trend of C20:5n-3, as observed in our sample, was not reported by Harris et al., but their sample may not be comparable to ours because of older age groups and the selection of patients whose blood samples were analysed for diagnostic purposes.

In a Hungarian sample of 188 healthy subjects including newborns, infants, children and young adults C18:2n-6 was positively associated with age ${ }^{28}$ confirming our results and those from others, ${ }^{29}$ whereas $\mathrm{C} 18: 0, \mathrm{C} 20: 4 n-6$ and $\mathrm{C} 18: 3 n-3$ were higher in children than in young adults. ${ }^{28}$ In contrast to our findings, C16:0, C20:5n-3, C22:6n-3, n-3 PUFA and n-3 LC PUFA showed a positive trend with age, whereas $C 20: 4 n-6, n-6$ PUFA and $n-6$ LC PUFA showed a negative trend. ${ }^{28}$

Recently, data of whole-blood FA composition of 2-9-year-old children of the Italian IDEFICS cohort were compared with neonates, adults and elderly from other Italian samples. ${ }^{40}$ C22:6n-3 levels of the 2-9-year-old children were found to be much lower as compared with neonates, adults and elderly. The authors concluded that this resulted either from lower intakes or from the fact that the rates of utilisation and resulting physiological requirements are higher than in adults. C18:3n-3, C18:2n-6, n-6 PUFA and total PUFA were lowest in neonates and increased progressively in children and adults, whereas monounsaturated FA in children were significantly lower than in adults and neonates. A positive trend of C18:2n-6, n-6 PUFA and total PUFA with age is in line with our data but we observed an inverse association of monounsaturated FA with age.

Whereas the Italian IDEFICS subsample included a high proportion of overweight and obese children, ${ }^{40}$ we constructed and applied weights to correct for the oversampling because studies showed an altered FA composition in obese children, ${ }^{46}$ for example, C22:6n-3 levels being inversely associated with the body mass index. ${ }^{16}$ However, our sensitivity analysis regarding the influence of obesity showed only minor differences in the percentile curves when obese children were included.

\section{Sex differences of FA}

In our sample, C20:3n-6, C20:4n-6 and C22:4n-6 seemed to be slightly higher in boys than in girls. In British school children, boys not only had higher mean C20:3n- 6 and C20:4n- 6 but also higher C22:5n-3 and C22:6n-3 than girls. ${ }^{44}$ In a large German cohort-in line with our results-6-year-old boys had higher C20:3n-6 and C22:4n-6 than girls. ${ }^{29}$

In Italian samples, among the main $\mathrm{n}-6$ and $\mathrm{n}-3$ PUFA only C18:2n-6 was significantly different in all groups (neonates, children, adults and elderly) being higher in females than in males. ${ }^{40}$

\section{Ratio and indices of FA percentages}

We also provide the $n-6 / n-3$ ratio and indices of enzyme activity that can be used as reference values for further studies. Ratios of $n-6 / n-3$ or $n-3 / n-6$ FA have been used in several studies to assess associations between the FA composition and health outcome or corresponding surrogate markers. ${ }^{47-50}$ Enzyme activity indices estimated from product/precursor ratios for SCD-1 (SCD-16, SCD-18), the rate-limiting enzymes in the biosynthesis of $C 16: 1 n-$ 7 and $C 18: 1 n-9$, and for D6D and D5D, required in the production of eicosanoids from C18:2n-6 and C18:3n-3, are important factors of the blood FA composition besides dietary intake. Studies have shown that obesity and metabolic syndrome are associated with high SCD-1 and D6D indices, and low D5D index. ${ }^{15,16,26}$ However, it is important to keep in mind that these activity indices were only estimated and not directly measured. Thus, our results need to be interpreted with caution because they reflect not only the influence of genetics including single-nucleotide polymorphisms and haplotypes but also the environmental and dietetic factors, such as the FA and carbohydrate intake, that can alter the FA composition and the desaturase activities.

\section{Strengths and limitations}

This is the first study that shows FA reference values for a large European sample of 3.0-8.9-year-old children. We have also reported the estimated enzyme activities that have not been provided before. However, as the dietary FA intakes were not analysed, we do not know whether the indicated reference ranges for PUFA correspond to dietary intakes that are in line with the recommendations.

\section{CONCLUSION}

Reported associations and causal relationship between the LC PUFA status and health-related outcomes increase the interest in FA determination. Therefore, the presented FA reference ranges of European children may be useful for the interpretation of the whole-blood FA composition. They provide a basis for comparison in epidemiological and clinical studies, and may also be used as an orientation for clinical practice in future. As the dietary intake does not meet the recommended daily amount for total PUFA and particularly not for $n-3$ LC PUFA in children and adolescents, ${ }^{51}$ the presented reference values for PUFA do not allow conclusions with regard to health outcomes. Prospective studies relating FA 
level to health outcomes are needed to determine target values of blood PUFA and particularly n-3 LC PUFA composition for primary and secondary prevention.

\section{CONFLICT OF INTEREST}

The authors declare no conflict of interest.

\section{ACKNOWLEDGEMENTS}

This work was done as part of the IDEFICS Study (www.idefics.eu). We gratefully acknowledge the financial support of the European Community within the Sixth RTD Framework Programme Contract No. 016181 (FOOD). The authors are grateful to the Volkswagen Foundation that financially supported the production of this supplement.

\section{DISCLAIMER}

The information in this document reflects the author's view and is provided as is.

\section{REFERENCES}

1 Ratnayake WM, Galli C. Fat and fatty acid terminology, methods of analysis and fat digestion and metabolism: a background review paper. Ann Nutr Metab 2009; 55: 8-43.

2 Marangoni F, Colombo C, Martiello A, Negri E, Galli C. The fatty acid profiles in a drop of blood from a fingertip correlate with physiological, dietary and lifestyle parameters in volunteers. Prostaglandins Leukot Essent Fatty Acids 2007; 76: 87-92.

3 Saadatian-Elahi M, Slimani N, Chajes V, Jenab M, Goudable J, Biessy C et al. Plasma phospholipid fatty acid profiles and their association with food intakes: results from a cross-sectional study within the European Prospective Investigation into Cancer and Nutrition. Am J Clin Nutr 2009; 89: 331-346.

4 Harris WS, Pottala JV, Varvel SA, Borowski JJ, Ward JN, McConnell JP. Erythrocyte omega-3 fatty acids increase and linoleic acid decreases with age: observations from 160,000 patients. Prostaglandins Leukot Essent Fatty Acids 2013; 88: 257-263.

5 Socha P, Ryzko J, Koletzko B, Celinska-Cedro D, Woynarowski M, Czubkowski P et al. Essential fatty acid depletion in children with inflammatory bowel disease. Scand J Gastroenterol 2005; 40: 573-577.

6 Jorgensen $\mathrm{MH}$, Ott $\mathrm{P}$, Michaelsen KF, Porsgaard T, Jensen F, Lanng S. Long-chain PUFA in granulocytes, mononuclear cells, and RBC in patients with cystic fibrosis: relation to liver disease. J Pediatr Gastroenterol Nutr 2012; 55: 76-81.

7 Clemmesen JO, Hoy CE, Jeppesen PB, Ott P. Plasma phospholipid fatty acid pattern in severe liver disease. J Hepatol 2000; 32: 481-487.

8 Wolfe I, Thompson M, Gill P, Tamburlini G, Blair M, van den Bruel A et al. Health services for children in western Europe. Lancet 2013; 381: 1224-1234.

9 Perrin JM, Bloom SR, Gortmaker SL. The increase of childhood chronic conditions in the United States. JAMA 2007; 297: 2755-2759.

10 Hwang I, Cha A, Lee H, Yoon H, Yoon T, Cho B et al. N-3 polyunsaturated fatty acids and atopy in Korean preschoolers. Lipids 2007; 42: 345-349.

11 Bolte G, Kompauer I, Fobker M, Cullen P, Keil U, Mutius E et al. Fatty acids in serum cholesteryl esters in relation to asthma and lung function in children. Clin Exp Allergy 2006; 36: 293-302.

12 Yu G, Bjorksten B. Polyunsaturated fatty acids in school children in relation to allergy and serum IgE levels. Pediatr Allergy Immunol 1998; 9: 133-138.

13 Maqbool A, Schall Jl, Gallagher PR, Zemel BS, Strandvik B, Stallings VA. Relation between dietary fat intake type and serum fatty acid status in children with cystic fibrosis. J Pediatr Gastroenterol Nutr 2012; 55: 605-611.

14 Olveira G, Dorado A, Olveira C, Padilla A, Rojo-Martinez G, Garcia-Escobar E et al. Serum phospholipid fatty acid profile and dietary intake in an adult Mediterranean population with cystic fibrosis. Br J Nutr 2006; 96: 343-349.

15 Abe Y, Okada T, Iguchi H, Saito E, Kuromori Y, Iwata F et al. Association of changes in body fatness and fatty acid composition of plasma phospholipids during early puberty in Japanese children. J Atheroscler Thromb 2012; 19: 1102-1109.

16 Saito E, Okada T, Abe Y, Kuromori Y, Miyashita M, Iwata F et al. Docosahexaenoic acid content in plasma phospholipids and desaturase indices in obese children. J Atheroscler Thromb 2011; 18: 345-350.

17 Patel PS, Sharp SJ, Jansen E, Luben RN, Khaw KT, Wareham NJ et al. Fatty acids measured in plasma and erythrocyte-membrane phospholipids and derived by food-frequency questionnaire and the risk of new-onset type 2 diabetes: a pilot study in the European Prospective Investigation into Cancer and Nutrition (EPIC)-Norfolk cohort. Am J Clin Nutr 2010; 92: 1214-1222.

18 Decsi T, Szabo E, Burus I, Marosvolgyi T, Kozari A, Erhardt E et al. Low contribution of $n-3$ polyunsaturated fatty acids to plasma and erythrocyte membrane lipids in diabetic young adults. Prostaglandins Leukot Essent Fatty Acids 2007; 76: 159-164.
19 Riemer S, Maes M, Christophe A, Rief W. Lowered omega-3 PUFAs are related to major depression, but not to somatization syndrome. J Affect Disord 2010; 123: 173-180.

20 Maes $\mathrm{M}$, Smith $\mathrm{R}$, Christophe A, Cosyns $\mathrm{P}$, Desnyder $\mathrm{R}$, Meltzer H. Fatty acid composition in major depression: decreased omega 3 fractions in cholesteryl esters and increased C20: 4 omega 6/C20:5 omega 3 ratio in cholesteryl esters and phospholipids. J Affect Disord 1996; 38: 35-46.

21 Antalis CJ, Stevens LJ, Campbell M, Pazdro R, Ericson K, Burgess JR. Omega-3 fatty acid status in attention-deficit/hyperactivity disorder. Prostaglandins Leukot Essent Fatty Acids 2006; 75: 299-308.

22 Mitchell EA, Aman MG, Turbott SH, Manku M. Clinical characteristics and serum essential fatty acid levels in hyperactive children. Clin Pediatr (Phila) 1987; 26: 406-411.

23 Kaikkonen JE, Jula A, Mikkila V, Juonala M, Viikari JS, Moilanen T et al. Childhood serum fatty acid quality is associated with adult carotid artery intima media thickness in women but not in men. J Nutr 2013; 143: 682-689.

24 Kaikkonen JE, Jula A, Mikkila V, Viikari JS, Moilanen T, Nikkari T et al. Childhood serum cholesterol ester fatty acids are associated with blood pressure 27 y later in the Cardiovascular Risk in Young Finns Study. Am J Clin Nutr 2012; 95: 1422-1431.

25 Saito E, Okada T, Abe Y, Odaka M, Kuromori Y, Iwata F et al. Abdominal adiposity is associated with fatty acid desaturase activity in boys: implications for C-reactive protein and insulin resistance. Prostaglandins Leukot Essent Fatty Acids 2013; 88: 307-311.

26 Vessby B, Gustafsson IB, Tengblad S, Berglund L. Indices of fatty acid desaturase activity in healthy human subjects: effects of different types of dietary fat. Br J Nutr 2013; 110: 871-879.

27 Laryea M, Cieslicki P, Diekmann E, Wendel U. Age-dependent fatty acid composition of erythrocyte membrane phospholipids in healthy children. Z Ernahrungswiss 1990; 29: 284-294.

28 Jakobik V, Burus I, Decsi T. Fatty acid composition of erythrocyte membrane lipids in healthy subjects from birth to young adulthood. Eur J Pediatr 2009; 168: 141-147.

29 Glaser C, Demmelmair H, Sausenthaler S, Herbarth O, Heinrich J, Koletzko B. Fatty acid composition of serum glycerophospholipids in children. J Pediatr 2010; 157: 826-831.

30 Ahrens W, Bammann K, Siani A, Buchecker K, De HS, lacoviello L et al. The IDEFICS cohort: design, characteristics and participation in the baseline survey. Int J Obes (Lond) 2011; 35: S3-15.

31 Cole TJ, Lobstein T. Extended international (IOTF) body mass index cut-offs for thinness, overweight and obesity. Pediatr Obes 2012; 7: 284-294.

32 Marangoni F, Colombo C, Galli C. A method for the direct evaluation of the fatty acid status in a drop of blood from a fingertip in humans: applicability to nutritional and epidemiological studies. Anal Biochem 2004; 326: 267-272.

33 Stasinopoulos DM, Rigby RA. Generalized additive models for location scale and shape (GAMLSS). R J Stat Softw 2007; 23: 1-46.

34 van BS, Fredriks M. Worm plot: a simple diagnostic device for modelling growth reference curves. Stat Med 2001; 20: 1259-1277.

35 Cole TJ, Stanojevic S, Stocks J, Coates AL, Hankinson JL, Wade AM. Age- and size-related reference ranges: a case study of spirometry through childhood and adulthood. Stat Med 2009; 28: 880-898.

36 de OM, Onyango AW, Borghi E, Siyam A, Nishida C, Siekmann J. Development of a WHO growth reference for school-aged children and adolescents. Bull World Health Organ 2007; 85: 660-667.

37 de OM, Lobstein T. Defining obesity risk status in the general childhood population: which cut-offs should we use? Int J Pediatr Obes 2010; 5: 458-460.

38 Kuczmarski, RJ Ogden, CL Guo, SS Grummer-Strawn, LM Flegal, KM Mei, Z et al. Vital and Health Statistics (Series 11, Number 246): 2000 CDC Growth Charts for the United States: Methods and Development. Department of Health and Human Services, CDC: Hyattsville, MD, USA, 2002, pp 1-190.

39 Rise P, Eligini S, Ghezzi S, Colli S, Galli C. Fatty acid composition of plasma, blood cells and whole blood: relevance for the assessment of the fatty acid status in humans. Prostaglandins Leukot Essent Fatty Acids 2007; 76: 363-369.

40 Rise P, Tragni E, Ghezzi S, Agostoni C, Marangoni F, Poli A et al. Different patterns characterize Omega 6 and Omega 3 long chain polyunsaturated fatty acid levels in blood from Italian infants, children, adults and elderly. Prostaglandins Leukot Essent Fatty Acids 2013; 89: 215-220.

41 Hodson L, Skeaff CM, Fielding BA. Fatty acid composition of adipose tissue and blood in humans and its use as a biomarker of dietary intake. Prog Lipid Res 2008; 47: 348-380.

42 Harris WS, Von SC. The omega-3 index: a new risk factor for death from coronary heart disease? Prev Med 2004; 39: 212-220.

43 Baylin A, Kim MK, Donovan-Palmer A, Siles X, Dougherty L, Tocco P et al. Fasting whole blood as a biomarker of essential fatty acid intake in epidemiologic studies: comparison with adipose tissue and plasma. Am J Epidemiol 2005; 162: 373-381. 
44 Montgomery P, Burton JR, Sewell RP, Spreckelsen TF, Richardson AJ. Low blood long chain omega-3 fatty acids in UK children are associated with poor cognitive performance and behavior: a cross-sectional analysis from the DOLAB study. PLOS One 2013; 8: e66697.

45 Albert CM, Campos H, Stampfer MJ, Ridker PM, Manson JE, Willett WC et al. Blood levels of long-chain n-3 fatty acids and the risk of sudden death. $N$ Engl J Med 2002; 346: 1113-1118.

46 Burrows T, Collins CE, Garg ML. Omega-3 index, obesity and insulin resistance in children. Int J Pediatr Obes 2011; 6: e532-e539.

47 Eriksson S, Mellstrom D, Strandvik B. Fatty acid pattern in serum is associated with bone mineralisation in healthy 8-year-old children. Br J Nutr 2009; 102: 407-412.

48 Kalogeropoulos N, Panagiotakos DB, Pitsavos C, Chrysohoou C, Rousinou G, Toutouza $M$ et al. Unsaturated fatty acids are inversely associated and $n-6 / n-3$ ratios are positively related to inflammation and coagulation markers in plasma of apparently healthy adults. Clin Chim Acta 2010; 411: 584-591.

49 Johnson M, Mansson JE, Ostlund S, Fransson G, Areskoug B, Hjalmarsson K et al. Fatty acids in ADHD: plasma profiles in a placebo-controlled study of Omega 3/6

fatty acids in children and adolescents. Atten Defic Hyperact Disord 2012; 4: 199-204.

50 Nozue T, Yamamoto S, Tohyama S, Fukui K, Umezawa S, Onishi Y et al. Effects of serum $n-3$ to $n-6$ polyunsaturated fatty acids ratios on coronary atherosclerosis in statin-treated patients with coronary artery disease. Am J Cardiol 2013; 111: 6-11.

51 Harika RK, Cosgrove MC, Osendarp SJ, Verhoef P, Zock PL. Fatty acid intakes of children and adolescents are not in line with the dietary intake recommendations for future cardiovascular health: a systematic review of dietary intake data from thirty countries. Br J Nutr 2011; 106: 307-316.

(c) (i) $($ This work is licensed under a Creative Commons AttributionBY NC ND NonCommercial-NoDerivs 4.0 International License. The images or other third party material in this article are included in the article's Creative Commons license, unless indicated otherwise in the credit line; if the material is not included under the Creative Commons license, users will need to obtain permission from the license holder to reproduce the material. To view a copy of this license, visit http:// creativecommons.org/licenses/by-nc-nd/4.0/

Supplementary Information accompanies this paper on International Journal of Obesity website (http://www.nature.com/ijo) 